\title{
Tomás de Suria, un dibujante de la expedición de Malaspina. Su contribución al conocimiento del occidente de Norteamérica
}

\author{
Águeda Jiménez Pelayo \\ Universidad de Guadalajara. \\ Guadalajara, Jal., México
}

Este trabajo está dedicado a destacar el papel de Tomás de Suria, dibujante de la Academia de San Carlos de la ciudad de México, en la expedición de Alejandro Malaspina. Se hacen algunas referencias al viaje alrededor del mundo y trata especialmente de las investigaciones realizadas en las costas de Canadá y Alaska. Se da énfasis a la importancia de la labor de los artistas para el conocimiento de los lugares visitados, centrándose en la obra artística de Suria. Comprende un análisis de la contribución de Suria como dibujante y las penalidades que tuvo que soportar para que su trabajo fuera reconocido. Se aprovecha también la valiosa información que proporciona Suria acerca de las costumbres de los nativos de Mulgrave y Nutka, pues con ella se enriquece la antropología y etnohistoria de estas regiones. A través de los dibujos de los artistas de la expedición tenemos un mejor conocimiento de la cartografía, geografía, geodesia, botánica, zoología y etnohistoria del noroeste de América.

En la segunda mitad del Siglo de Las Luces, como un resultado del notable interés europeo en las ciencias, varias naciones realizaron viajes marítimos alrededor del mundo, con el fin de ampliar los conocimientos acerca de la geología, cartografía, geografía y etnohistoria. Los ingleses y franceses recibieron el apoyo imperial para realizar estas expediciones, entre los primeros se distinguieron George Anson, John Byron y Philip Carteret; más tarde James Cook y otros. Entre las más destacadas exploraciones francesas del siglo XVIII se pueden mencionar las de La Condamine (1735-1744), Louis Antoine Bougainville (1766-1769), y la del conde de La Pérouse (1785-1788). ${ }^{1}$

España también participó en la organización de empresas marítimo científicas ilustradas, principalmente durante los reinados de Carlos III y Carlos IV. El área geográfica de mayor interés para los iberos abarcaba los territorios españoles en América y Asia.

1 Beals, Herbert K.:"Malaspina precursors New Light on Spanish Voyages to the Northwest Coast of America 1774-1779". Malaspina '92, pág. 162. Para conocer una amplia y reciente historiografía sobre el tema, véase Sáiz, Blanca:Bibliografía sobre Alejandro Malaspina y acerca de la expedición Malaspina y de los marinos y científicos que en ella participaron, Madrid, 1992. También La expedición Malaspina, 1789-1794, Ts. IV (Trabajos científicos y correspondencia de Tadeo Haenke) y T. V (Antropología y noticias etnográficas). Estudio de M. ${ }^{a}$ V. Ibáñez Montoya. Madrid, 1993. 
Varios motivos influyeron para que se llevaran a cabo, entre ellos los fines políticos del Estado y la organización institucionalizada que proporcionó medios e infraestructura para la renovación de la armada, lo cual sería un instrumento vital en el desarrollo de la ciencia. Las expediciones fueron sistematizadas y custodiadas, en su mayor parte, por las instituciones científicas de la propia marina, como el Observatorio Astronómico y el Depósito Hidrográfico. ${ }^{2}$

Asimismo se llevó a cabo un programa de la marina y la armada para reforzar el control de la administración ultramarina y para responder a la amenaza que se presentaba en los mares. La presencia en aumento de rusos, franceses e ingleses exigía un rápido control marítimo desde Magallanes hasta Alaska, las Filipinas y otros archipiélagos del Pacífico, reforzando la presencia española en la Polinesia y reorganizando rutas comerciales alternas y nuevos puestos de abastecimiento.

Los iniciadores del impulso europeista de la marina española fueron sin duda Jorge Juan y Antonio de Ulloa en 1734. Este interés continuó en la generación de marinos de 1783, en el Observatorio de Cádiz, alrededor de Vicente Tofiño. La política de Estado demandaba con más urgencia "nueva y moderna cartografía levantada por españoles que evitara la dependencia de la cartografía elaborada por extranjeros". ${ }^{3}$ La Corona española otorgó valiosa ayuda a las ciencias naturales europeas con la organización de expediciones científicas a América entre 1775 y 1800.

Una de las más grandes empresas científico políticas organizada por el Estado Español fue la dirigida por Alejandro Malaspina, de 1789 a 1794. Según María Dolores Higueras, esta expedición reúne los ideales intelectuales, políticos y científicos de una tardía ilustración y con ella culmina la expansión marítima española de la Edad Moderna. ${ }^{4}$

Entre los objetivos del viaje, se incluían: establecer los puertos más adecuados para la marina militar; asegurar las rutas marítimas comerciales; informar sobre la situación defensiva en las costas y puertos, averiguar el estado de los puestos extranjeros de la región y cartografiar las costas del Pacífico. ${ }^{5}$ Les interesaba también la investigación acerca de la verdad o falsedad de la existencia de un paso entre los dos océanos; y recomendar alter-

2 Pimentel Igea, J.F.: Malaspina y la Ilustración, Madrid, 1989. Higueras, María Dolores:"El marino ilustrado y las expediciones científicas". La Botánica en la expedición de Malaspina 17891794. Madrid, 1989, pág. 16.

3 Higueras: "El marino...", págs. 17-21.

4 Ibídem, págs. 21-22.

5 Ibídem, págs. 23-25. 
nativas respecto a la posición política de España en la costa noroeste del Pacífico. Por estos motivos era necesario examinar físicamente el territorio de Alaska y las costas canadienses, no reconocidas previamente por Cook, Dixon, La Pérouse y los marineros españoles que zarparon de San Blas. Otras actividades serían: el trazado de mapas, la investigación geológica y etnográfica, cálculos sobre la gravedad y observaciones astronómicas, lo mismo que estudios acerca de la flora y la fauna del noroeste. Como un complemento para la investigación y para ilustrar mejor las actividades realizadas, las expediciones contaban con los servicios de artistas que actuaban como dibujantes de especímenes de botánica y zoología, lo mismo que de nativos, paisajes y mapas. ${ }^{6}$

Durante su recorrido por las costas americanas, los expedicionarios visitaron Montevideo, Río de la Plata, la Patagonia, las islas Malvinas y las Aurora, Chile, Perú, Ecuador, Colombia, Panamá, Centroamérica, la Nueva España, California y la costa noroeste del Pacífico hasta Alaska; de regreso hacia el sur, cruzaron el Pacífico y se dirigieron a las Marianas, Filipinas y Vavao, Macao, Nueva Zelanda y Australia. ${ }^{7}$

\section{El viaje de Malaspina}

El hombre que planeó el viaje al círculo del globo, fue Alejandro Malaspina, nacido en 1754 en Mulazzo, en el ducado de Parma. Se unió a la marina española a los veinte años y en 1784 circunnavegó la tierra en dirección oeste. Debido a esta experiencia concibió la idea de realizar una expedición científica exploradora. Pronto encontró apoyo en el ministro español de Marina, Antonio Valdés. ${ }^{8}$ Para llevar a cabo el viaje se construyeron dos corbetas: la "Descubierta" y la "Atrevida", las cuales fueron provistas con su tripulación, oficiales necesarios y personal técnico, en los que recaía la responsabilidad científica.

6 Alejandro Malaspina. Diario General del viaje. La expedición Malaspina 1789-1794. Estudio de Ricardo Cerezo Martínez, T. II, vol. 1. ${ }^{\circ}$, Madrid, 1987. González Claverán, Virginia:La expedición científica de Malaspina en Nueva España, 1789-1794. México, 1988. Novo y Colson, Pedro de:La vuelta al mundo por las corbetas "Descubierta" y "Atrevida" al mando del capitán don Alejandro Malaspina desde 1789 a 1794, Madrid, 1885. Destefani, Laurio H.; Cutter, Donald: Tadeo Haenke y el final de una vieja polémica, Buenos Aires, 1945. Varios Autores:La expedición Malaspina, 1789-1794. Viaje a América y Oceanía de las goletas “Descubierta” y “Atrevida”. Madrid, 1984.

7 Destefani y Cutter:Tadeo Haenke...

8 González Claverán:La expedición ... Novo y Colson: La vuelta ... Cutter, D.:Malaspina in California, San Francisco, 1960, pág. 1. 
La expedición zarpó de Cádiz el 30 de julio de 1789; visitaron Río de La Plata, y posteriormente atravesaron el Cabo de Hornos y continuaron sus trabajos en Chile y Perú. ${ }^{9}$ Panamá, Realejo y Acapulco fueron los siguientes puertos de escala:en febrero llegó la "Atrevida" a Acapulco, después visitó San Blas y finalmente se reunieron las dos corbetas en Acapulco. ${ }^{10}$ De este puerto Malaspina viajó a la ciudad de México para entrevistarse con el virrey Revillagigedo. Antes de continuar el viaje decidió dejar una comisión de ocho científicos para realizar investigaciones en la Nueva España. ${ }^{11}$

Cuando Malaspina se encontraba en la costa sudamericana pensaba que, tal vez, ya no sería conveniente, ni necesario, hacer el viaje al noroeste de América. Sin embargo, órdenes de España determinaron que la visita debería realizarse. El motivo principal, tal como se había proyectado en 1789, era investigar las reclamaciones hispanas y las de sus rivales sobre el noroeste. En 1790 el asunto de la soberanía sobre la costa norte del Pacífico pasó a primer plano en la controversia de la Rada de Nootka o Nutka.

El comandante esperaba que el asunto ya habría sido decidido en las negociaciones que se realizaban en Europa y que su presencia en la costa del noroeste no sería necesaria. Pero el ministro de Marina determinó que el capitán hiciera una inspección más minuciosa de la costa que la realizada por las expediciones españolas previas: las de Juan Pérez, Esteban José Martínez, Ignacio Arteaga, Juan de la Bodega y Cuadra y otras. Además, aunque para entonces se creía improbable, no estaba definitivamente determinado si había o no un pasaje que conectara los dos océanos, lo cual seguía siendo un misterio. ${ }^{12}$

\section{Los pintores de la expedición}

En el siglo XVIII el dibujo se había convertido en un instrumento indispensable para el desarrollo de los estudios geográficos, botánicos, zoológicos y antropológicos dentro de las expediciones científicas. La úni-

9 Ratto, Héctor:La expedición de Malaspina (siglo XVIII), Buenos Aires, 1945, págs. 19-25. Destefani y Cutter:Tadeo Haenke ..., pág. 25.

10 Sanfeliú Ortiz, Lorenzo de: 62 meses a bordo. La expedición Malaspina según el diario del Teniente de Navío don Josep de Tova y Arredondo, 2. ${ }^{\circ}$ Comandante de la "Atrevida". Madrid, 1943, pág. 120.

11 Sobre las investigaciones de la comisión que permaneció en la Nueva España, véase González Claverán: La expedición ...

12 Cutter: Malaspina in California, pág. 6. 
ca forma de conservar imágenes de las tierras que visitaban era a través de dibujos, bocetos, diseños o pinturas. Así, la labor del pintor o dibujante consistía en describir por medio de su obra artística las costumbres, trajes, danzas y viviendas; hacer retratos de los nativos y dibujos de animales y plantas.

Como lo afirma Carmen Sotos Serrano, el dibujo ocupó un lugar muy destacado durante el siglo XVIII; para que los trabajos naturalistas que se llevaban a cabo en las expediciones adquiriesen el máximo rigor científico, se necesitaba que dibujaran al natural las especies recogidas antes de disecarlas. El dibujo constituía, por tanto, la única herramienta capaz de ofrecer al investigador las características más intrínsecas y relevantes. Por más detallada que fuera la descripción escrita, no proporcionaría la fidelidad suficiente al modelo natural representado. Gracias a estos trabajos, los científicos de aquella época y los actuales pueden clasificar los especímenes encontrados. ${ }^{13}$

Al partir la expedición de Cádiz contaba con los servicios de dos artistas: José del Pozo, a bordo de la "Descubierta", y José Guío en la "Atrevida". Del Pozo, pintor sevillano, realizó su obra pictórica principalmente en Río de la Plata y Chile. Según Malaspina, era un hombre con algo de talento, pero indisciplinado, flojo y no apto para su misión, por lo cual fue destituido al llegar al Perú. ${ }^{14}$ Guío se dedicó casi totalmente a reproducir plantas y a adelantar con algún éxito el estudio de la historia natural, a la que era muy inclinado; pero gozaba de poco favor a bordo y su salud no era buena, por lo que se pensó dejarlo en Acapulco. ${ }^{15}$ Sin, embargo Sotos Serrano considera que es sorprendente que se despidiera a Guío, ya que de acuerdo con los informes de sus superiores, su comportamiento y su asiduidad al trabajo fueron intachables. Supone que tal vez haya influido el hecho de que "no llenaba los grandes fines de la expedición". Su labor era muy especializada, estaba encargado del dibujo botánico y de la disección, pero estas actividades no constituían el objetivo primordial del viaje. ${ }^{16}$

Cuando Malaspina decidió despedir a los dos artistas, escribió a España para pedir suplentes. Los italianos Juan Ravenet y Fernando Brambila fueron contratados, pero no se unieron a ellos hasta después del

13 Sotos Serrano, Carmen:"La botánica y el dibujo en el siglo XVIII", en Los pintores de la expedición de Alejandro Malaspina, Madrid, 1982, vol. I, págs. 73-74.

14 Ratto: La expedición ..., págs. 30-31.

15 Ibídem, págs. 35-36. Cutter:Malaspina in California, pág. 12.

16 Sotos Serrano:Los pintores ..., vol. I, págs. 77-79. 
viaje a California, por lo tanto fue necesario buscar otros dibujantes para la expedición a la costa norte del Pacífico. ${ }^{17}$

Casi simultáneamente a la partida de Del Pozo, comenzó a trabajar como artista José Cardero, quien iba en la tripulación como primer contramaestre..$^{18}$ Es posible que haya iniciado su actividad como pintor en Montevideo con una vista de la Colonia de Sacramento; acerca de este dibujo Sotos Serrano comenta:

"La panorámica como tal es pobre y carente de interés artístico, en ella el autor denota su desconocimiento de la perspectiva, así como una falta de soltura en el dibujo que le hace trazar con rigidez y a escala muy reducida, respecto del conjunto representado, las casas y el paisaje que forman". ${ }^{19}$

Sin embargo, las primeras informaciones documentadas sobre Cardero como dibujante, durante la expedición, provienen de Guayaquil. En Lima, después de haberse retirado José del Pozo, Cardero pasó a ser el único pintor de ella dedicado a la botánica, durante la trayectoria de esta ciudad a Acapulco.

Este dibujante desempeñó un papel importante, ya que se le encomendó la valiosa tarea de encargarse de modo oficial —mientras llegaban de Italia, los pintores contratados- de elaborar distintas vistas y dibujos de los lugares y objetos de mayor interés. Su labor en Ecuador, no se limitó a la perspectiva, sino que, como lo destaca Sotos Serrano, fue más importante la ayuda que prestó a los naturalistas. El dibujante continuó su tarea en Panamá y las islas y puertos visitados durante la travesía, rumbo a Acapulco. Dibujó panorámicas y a la vez especies raras, principalmente de peces y aves. ${ }^{20}$

De doce láminas que se conservan de Guayaquil, en las que diseñó diversas clases de aves de hermosos plumajes, se puede apreciar que el resultado es muy superior al logrado en las perspectivas de la ciudad, lo que, como afirma Sotos Serrano, "indica una mayor experiencia o facilidad en el pintor para el dibujo de los animales". Además, también se aprecia en las perspectivas cierto progreso en su estilo al conseguir una mayor soltura en el dibujo y en la composición, fruto del empeño y afán de superación del

17 Ratto: La expedición ..., pág. 33.

18 José Antonio Feliciano Cardero era originario de Ecija y había nacido el 20 de octubre de 1766; debía tener 23 años cuando fue contratado para la expedición. Sotos Serrano: Los pintores..., vol. I, pág. 125.

19 Ibídem.

20 Ibídem, págs. 126-127. 
artista. Al llegar la "Descubierta" a Acapulco, Cardero continuó su trabajo, trazó perspectivas e hizo dibujos en colores de aves y peces. Tal vez por falta de confianza, en sus primeros trabajos dibujó con menos licencia artística, pero con más precisión que muchos de sus contemporáneos. Esta fidelidad para los detalles ha servido de gran ayuda a los historiadores. En el noroeste hizo dibujos de las costumbres de los nativos, tipos indígenas y escenas generales de la región. ${ }^{21}$

Sin embargo, desde Guayaquil, Malaspina ya había escrito al virrey de México para solicitar que contratara algún pintor de la Academia de San Carlos, para que los acompañara en el viaje al norte del Pacífico mientras llegaban los artistas españoles que había solicitado en Lima. Por lo tanto se unió a la expedición el grabador Tomás de Suria, quien junto con Cardero realizó la obra pictórica en esta parte de la expedición. ${ }^{22}$

\section{Tomás de Suria y su Diario}

El objetivo del presente trabajo es destacar las aportaciones de Suria en el conocimiento de la flora y la fauna del noroeste de América, de las exóticas costumbres de los nativos, y al mismo tiempo señalar la contribución de esta expedición en el delineamiento de las costas y conocimiento de la ubicación de montañas, glaciares, bahías e islas.

En 1778 se embarcaron para la Nueva España don Jerónimo Antonio Gil y sus discípulos Tomás de Suria y José Estebe, alumnos de la Real Academia de San Fernando de Madrid. La invitación a pasar a América junto con su maestro debió, sin duda, ser una proposición atractiva para Suria y su compañero.

Desde su llegada a México Suria trabajó como tallador en la Casa de Moneda de la capital mexicana, y seis años más tarde fue pensionado de la misma institución. A pesar de contar tan sólo diecisiete años de edad, era excelente grabador de medallas y, además, él mismo afirmaba ser uno de los dos artistas que, junto con Gerónimo Antonio Gil, fundaron la Real Academia de San Carlos. ${ }^{23}$ Este otro notable artista había nacido en Ma-

21 Ibídem, págs. 127-128.

22 Cutter, D.C.:"Early Spanish Artists on the West Coast", Pacific Northwest Quarterly, October 1963, pags. 151-152.

23 Fernández, Justino:Tomás Suria y su Viaje con Malaspina, 1791, México, 1939, pág. 20. Archivo de la Antigua Academia de San Carlos (en adelante AASC), Manuscrito 1962, Suria a Andrés Mendívil, 28 de febrero de 1826. 
drid, en abril de 1761 y el año en que se inició la expedición trabajaba en San Carlos, tenía dos hijos y residía en la misma casa que sus parientes políticos en México. ${ }^{24}$

Desde Guayaquil, el comandante Alejandro Malaspina se comunicó con el virrey de México, segundo conde de Revillagigedo, para pedirle un dibujante que supliera a José del Pozo. Agregaba que "fuera muy útil para la comisión, una u otra persona experta en el dibujo y en la perspectiva, aunque no lo fuese en el colorido, que quisiese seguirnos en esa campaña y restituirse luego a México". El sueldo sería de 500 a 800 pesos anuales, tendría alojamiento y mesa decentes y se uniría a la expedición en San Blas o Acapulco. ${ }^{25}$

Revillagigedo escribió al presidente de la Junta de la Real Academia de San Carlos, Ramón Posada, y le solicitó que escogiera a quien quisiera voluntariamente hacer el viaje entre los alumnos más adelantados. Posada notificó al director, Jerónimo Antonio Gil, la orden del virrey y éste propuso a Tomás de Suria y otros tres pintores. Suria fue quien reunió los requisitos exigidos y aceptó llevar a cabo la misión; era hombre animoso y se sentía atraído por la aventura de visitar lugares lejanos y misteriosos. Sin embargo debe haber pensado en los riesgos que suponía unirse a la expedición, puesto que pidió que si moría se le siguiera pagando la pensión que recibía a su esposa. ${ }^{26}$

Las excelentes recomendaciones contribuyeron a que obtuviera el empleo bajo las condiciones que el mismo exigía. Posada lo consideraba un artista hábil en el grabado y la pintura, "sujeto de buenas circunstancias, el más aprovechado de cuantos hay en la capital en proporción". ${ }^{27}$ El dibujante puso sus condiciones para aceptar el trabajo: sueldo de 1.000 pesos, más la pensión que recibía de 600, la cual se entregaría a su esposa, conservar su empleo y los derechos adquiridos durante doce años de servicios, prin-

24 Sus padres fueron Francisco Suria y Feliciana Lozano. Contrajo matrimonio con María Josefa Fernández de Mendoza, hija de Joaquín Fernández y Josefa Molina. Jiménez Pelayo, Agueda:Tomás de Suria y su participación en la expedición al noroeste de América. Tesis de Maestría, The University of New Mexico, Albuquerque, New Mexico, 1972, pag. 105.

25 Archivo General de la Nación, México (en adelante AGN), Historia, 197, Malaspina al virrey, 16 de octubre de 1790 .

26 Ibídem. Entre los candidatos estaba Francisco Lindo, de quien no dio buenas recomendaciones Posada, pues se refirió a él como un dibujante que no tenía práctica en la perspectiva; sin embargo, fue comisionado para compañar a Antonio Pineda y Née en la investigación que hicieron en territorio mexicano.Sotos Serrano (Los pintores ..., pág. 152) comenta que su estilo era bastante pobre, tal vez debido a su juventud y falta de experiencia

27 AGN, Historia, 397, Posada al virrey, 19 de enero de 1791. 
cipalmente respecto a los ascensos, recibir 200 pesos para gastos de viajes, y tener "mesa decente de primera clase". ${ }^{2}$

El virrey informó que Suria se embarcaría con el comandante de la Expedición del Círculo del Globo, don Alejandro Malaspina, para trabajar en lo que se ofreciera en dibujo y perspectiva, añadiendo que el dibujante ya había convenido en las condiciones de trabajo. Suria recorrió 110 leguas a caballo para llegar a Acapulco y finalmente en febrero se embarcó en la "Descubierta". ${ }^{29} \mathrm{Al}$ unirse el dibujante a la expedición, Malaspina opinó en su Diario: "Don Tomás de Suria sujeto muy experto, así en el dibujo como en el grabado y dependiente de la Real Casa de Moneda en México". ${ }^{30}$

A bordo de esta nave escribió Suria un Diario particular que inició desde su llegada al puerto de Acapulco, el cual proporciona rica información sobre el viaje. Para este trabajo se utilizan el Diario mencionado y el Diario del teniente Antonio de Tova y Arredondo, segundo comandante de la "Atrevida" ${ }^{31} \mathrm{Al}$ comparar ambos diarios se debe tener en cuenta que Tova y Arredondo era marino de profesión, por lo tanto sus datos sobre la navegación tienen mayor valor que los de Suria, quien tenía pocos conocimientos sobre viajes marítimos; él mismo comenta que aunque quería obtener información, los marinos no se la proporcionaban. Sin embargo, describe con exactitud y gracia muchos incidentes interesantes de la travesía y da numerosos detalles sobre las costumbres de los pueblos visitados.

\section{Rumbo al noroeste}

Desde el 17 de febrero hasta fines de abril Suria trabajó en Acapulco. Las dos corbetas zarparon de este puerto el $1 .^{\circ}$ de mayo, y se dirigieron hacia el noroeste. El punto de reunión sería Mulgrave (Alaska), a donde llegaron el 23 de junio, después de 54 días de navegación. Durante el viaje se visitaban los comandantes y oficiales de las embarcaciones con el fin de cambiar mapas, comparar latitudes y longitudes y ponerse de acuerdo sobre las maniobras que debían realizar. Suria comenta los acontecimientos que rompían la monotonía del viaje, como las fiestas a los oficiales; el 30 de mayo, celebraron la onomástica de Fernando Quintero brindando con un exquisito vino malagueño, que había adquirido un grado de excelencia inexplicable al pasar el Cabo de Hornos.

28 Ibídem, 13 de enero de 1791.

29 Ibídem.

30 Alejandro Malaspina.Diario General ..., T. II, vol. 1. ${ }^{\circ}$, pág. 275. 
Es interesante la información que proporciona el artista acerca de los problemas de la travesía, como las precauciones que se tomaban en los barcos para evitar enfermedades, y el mal tiempo con "mares gruesas". Así, anota que en la latitud de Monterrey (California) a 224 leguas de la costa, a causa del mal tiempo se rompió el trinquete, y "fue cosa de risa la comida, pues andaban los platos y todo lo demás rodando sin que nadie los pudiera contener". ${ }^{32}$

Sobre las condiciones en que viajaban comenta:

"no quiero tratar de las incomodidades porque no es de este lugar, sólo diré que tendido en mi cama doy con los pies en el costado de la corbeta y con la cabeza en el mamparo (que así llaman a las tablas que cierran el camarote) y desde el pecho a la cubierta que es mi techo hay cuatro dedos de distancia cuya estrechura no me deja menear en la cama y necesito hacerme un rollo cubriéndome la cabeza aunque me sofoque pues es menos mal que verse acometer por millares de cucarachas de que tanta peste han ocasionado que a algunos individuos les hacían llagas en la frente y puntas de los dedos". ${ }^{33}$

En el Diario, Suria registra también la latitud a que se encuentran cada día, la dirección del viento y rumbo de la navegación, lo mismo que problemas técnicos en las corbetas. Frente a las Islas de la Reina Carlota, a los 52 de latitud, don Tomás se maravilla de que a las 8:45 de la tarde - "porque con luz diurna no se puede llamar noche"- el sol se acaba de poner, pero queda un crepúsculo hasta las 10; amanece a las dos y sale el sol a las 2:30 (A.M.); el dibujante disfruta por tener la oportunidad de contemplar estos fenómenos tan diferentes a los de México. ${ }^{34}$

31 El manuscrito original del Diario de Suria pertenece a la Colección Coe de la Biblioteca de la Universidad de Yale; está incompleto, pues le faltan algunos folios relativos a las estancias en Nutka y en Monterrey. El documento tiene un título que dice "Primer cuaderno", lo que hace suponer que hay un "Segundo cuaderno" referente al viaje desde la salida de Nutka.Henry Raup Wagner, historiador y bibliófilo, tradujo y editó la Primera parte del Diario de Suria en Journal of Tomás de Suria of this Voyage with Malaspina to the Northwest Coast of América in 1791, Glendale, Cal., 1936. Ese mismo año se autorizó la reimpresión en Pacific Historical Review, September 1936.Y en 1939 aparecía una traducción española, aunque no literal, del doctor Justino Fernández,en su Tomás de Suria ... En 1980 se reprodujo en inglés la edición de Wagner, con el mismo título y con introducción y notas de Donald C. Cutter, publicada en Washington, D.C. Para este trabajo se han utilizado microfilms del manuscrito original, que se cita como Suria, Diario. Aparece también el Diario de Antonio de Tova y Arredondo, cuyo original se encuentra en la Biblioteca Municipal de Santander, España, y que se cita como Tova y Arredondo, Diario, pero, al no haberse contado con una copia del original, se aprovechó la información aportada por Sanfeliú Ortiz: 62 meses a bordo.

32 Suria, Diario.

33 Ibídem.

34 Ibídem. 
El 23 de junio vieron tierra por primera vez después de su salida de Acapulco: era el Cabo Engaño. ${ }^{35}$ Suria trazó vistas de la costa y el geógrafo Bauzá hizo otras y determinó la longitud; además notó que todos los relojes adelantaron su movimiento. ${ }^{36}$ En estos lugares Bauzá y Suria continuaron dibujando montañas, costas, cabos y bahías.

Cuatro días después, las corbetas se encontraban en la bahía del puerto de Mulgrave. ${ }^{37}$ Bauzá vio un abra que dividía la cordillera, formando un pequeño estrecho; grande fue la alegría de Malaspina y sus oficiales, pues creyeron que podía ser el tan deseado estrecho que unía los dos océanos. Ferrer Maldonado situaba el estrecho en la misma latitud en que se hallaban: $59^{\circ} 31^{\prime}$. Finalmente anclaron en el puerto de Mulgrave, descubierto por La Pérouse en 1786, pero explorado y nombrado Mulgrave por Dixon en 1787. Un pedazo de costa antes de llegar al puerto Príncipe Guillermo aún no se conocía, por lo que decidieron explorarlo.

A una legua del puerto se realizó el primer encuentro con los nativos del lugar, hoy conocidos como Tlingit. La primera impresión fue una gran admiración mútua entre indios y españoles; los nativos "no se hartaban de mirar las embarcaciones", aunque advirtieron los marinos que no eran las primeras que veían. ${ }^{38}$

Para los expedicionarios fue impresionante ver a los naturales. Según Suria, vestían con pieles que parecían ser de oso, tigre, león, venado o marmotas, con el pelo para afuera; con una piel se cubrían de la cintura hacia abajo y otra pendía del hombro a manera de capa, llegando hasta las rodillas; las pieles eran de varios colores, bien curtidas, grandes y flexibles. El aspecto de los nativos no era desagradable, aunque sí salvaje; los colores con que se pintaban los desfiguraban enteramente, pues según los españoles parecía que mientras más horribles se veían, se consideraba de mayor lujo el adorno. Su pelo era grueso y lo llevaban sin ningún arreglo,

35 El capitán Cook les nombró cabo y monte Edgecumbe; Bodega y Cuadra llamó Engaño al cabo y San Jacinto al monte.

36 Tova y Arredondo, Diario.

37 Bahía Yakutat, en Alaska. Mulgrave fue descubierto por La Pérouse, pero recibió ese nombre por el inglés Constantine John Phipps, conde de Mulgrave. La bahía más grande es la de Yakutat, en la cual Mulgrave forma una pequeña parte.

38 Los nativos de la bahía de Yakutat pertenecen a la familia lingüística Tlingit, de la costa noroeste de América. Se adornan los labios con piezas de madera de gran tamaño, viven de la caza, la pesca y el comercio, y se distinguen por su habilidad para la navegación, según Wagener: Journal. Un estudio muy completo acerca de los Tlingit es el de Laguna, Frederica:Under Mount Saint Elias: The History and Culture of the Yakutat Tlingit. Washington, 1972.

39 Suria, Diario. 
ni aseo, suelto y untado de almagre y grasa que, según el olor, parecía de venado. ${ }^{39}$

Los naturales navegaron hacia los viajeros en dos canoas, al acercarse se pusieron de pie y "al sonido de una voz espantosa y amenazante que dio el más feo", todos a compás extendieron los brazos en cruz y entonaron un canto triste, pero lleno de armonía y cadencia; se componía sólo de tres notas, aunque el compás variaba. Esta recepción se consideró como un signo de paz.40

Durante la estancia de Malaspina y sus hombres en Mulgrave, la relación con los naturales fue amistosa, aunque no dejaron de suscitarse algunos conflictos. Desde el principio se realizó el trueque de diferentes productos. Los nativos cambiaban con los expedicionarios pieles de nutria por cuentas de vidrio; además, a cambio de botones, los indios les daban magnífico salmón fresco al precio de uno por botón, o un pequeño clavo. Suria considera este pescado como el más delicioso que se podía imaginar, por lo cual nunca se satisfacían los marinos, a pesar de comerlo en abundancia. ${ }^{41}$ Tova y Arredondo comenta que eran unos pescados exquisitos "que en Europa se miran como ornamentos de mesas suntuosas, y en el puerto de Mulgrave llegaron a ser desdeñados por los propios marineros". ${ }^{42}$ Los nativos también canjeaban sus útiles de pesca, muebles, armas y otros objetos de manufactura propia, por ropa vieja, clavos, cascabeles y otros artículos semejantes.

Los conflictos surgieron por robos que hacían los tlingit cuando subían a cubierta. Como en el caso del robo de un arpón y un candado, la chaqueta de Luis Pesoni y un gorro. En otra ocasión, el hurto de unos "calzones" ocasionó un serio problema. ${ }^{43}$ Para evitar robos, los marinos presionaban suspendiendo el comercio y los objetos robados eran regresados. Por su parte, los naturales tomaban rehenes para exigir que continuara el comercio. No faltaban casos en que los indígenas amenazaran con sus

\footnotetext{
40 Tova y Arredondo, Diario.

41 Suria, Diario. Según Malaspina, se fijó el precio de un salmón por un clavo de 3 a 3 y media pulgadas. Malaspina Diario, pág. 310.

42 Tova y Arredondo, Diario.

43 Curiosamente Wagner confundió el término "calzones", usado en el Diario de Suria, y lo tradujo como goats (cabras). Justino Fernández, al hacer la publicación en español sin haber tenido acceso al texto original, lo tradujo como cabras. En mi Tesis de Maestría antes citada aclaré éste y otros errores de Wagner y Cutter, en la reedición en inglés de 1980, menciona en la Introducción, pero no en notas junto al texto correspondiente, estas aclaraciones que encontré al confrontar la obra de Wagner con el texto original en español. Al ver el dibujo de Cardero que representa a los nativos en una canoa enarbolando unos pantalones, para obtener la paz, queda perfectamente aclarado el error.
} 
puñales, por lo que los españoles respondían con las estrategias utilizadas desde el siglo XVI, realizando prácticas de tiro al blanco, para manifestar indirectamente a los naturales la terrible fuerza de sus armas y la ventaja que tenían sobre las de los nativos. A pesar de estas pequeñas dificultades, no se menciona ningún caso de heridas graves o muerte de gente de ninguno de los bandos, aunque en ocasiones estuvieron a punto de entablar una lucha armada.

La estancia en Mulgrave tuvo resultados muy positivos en todos los aspectos. Se logró comprobar que el estrecho de Ferrer Maldonado no existía; se tomaron las latitudes y longitudes del puerto y lugares cercanos; se exploraron las islas vecinas y glaciares; se delineó la costa; se hicieron estudios sobre la flora y fauna del lugar; hubo gran aportación para la etnografía con el minucioso estudio sobre los naturales.

Concretándonos a nuestro artista, en Mulgrave es donde tuvo oportunidad de desarrollar una labor más minuciosa; a través de sus dibujos dio al mundo una idea clara y precisa de aquellos hombres de tan distantes latitudes y exóticas costumbres. Así, aunque delineó la costa y dibujó las montañas, glaciares, islas y la bahía de Yakutat, su labor más valiosa consistió en los dibujos que elaboró de los indios, sus habitaciones y armaduras; un solo diseño nos basta para conocer a los de Mulgrave. No fue ésta la única contribución de Suria; su Diario proporciona detalles que no es posible encontrar en otros documentos. Observador agudísimo, trata de profundizar para comprender la psicología de los tlingit: su experiencia por haber vivido trece años en Nueva España, donde tuvo conocimiento de los nativos, la aprovecha para hacer comparaciones entre los naturales de México y los de la costa noroeste del Pacífico.

\section{Estancia en Nootka}

De Mulgrave, Malaspina continuó el viaje el 8 de julio hacia las regiones del norte, vieron el cabo Hinchinbrook, a la entrada de la ensenada del Príncipe Guillermo; entraron en el canal que forman la isla Montague y la isla Magdalena; ahí estaban a los $61^{\circ}$ minutos, lo que excedía las órdenes de la corte, que le mandaban llegar a los 60 grados de latitud. ${ }^{44}$ De regreso, pasaron por las islas Hijosa, visitadas y nombradas anteriormente por marinos españoles.

44 La isla Magdalena, según Suria, había sido descubierta por Bodega y Cuadra. 
Hubo deliberaciones a bordo sobre si se subía a los 70 u 80, en donde por el estrecho de Behring se unen los dos océanos para hacer los reconocimientos de las costas exploradas por Cook. Partieron el 8 de julio y durante cuatro días no vieron la costa a causa del viento, el día 13 aclaró un poco y descubrieron al oeste la costa y algunas islas; según la traducción de Wagner, los pilotos opinaron que eran las islas "Ami", pero lo que Suria escribe en su Diario es: "Ami [A mí] no me parezen tales". ${ }^{45}$

Despúes de haber llegado a la entrada de la Ensenada del Príncipe Guillermo, y con la temporada avanzada, Malaspina decidió abandonar el proyecto y regresar hacia el sur. Según Suria, hasta los más humildes marineros, empezaron a murmurar y se les notaba disgusto e impaciencia, porque habían sabido que los ingleses les llevaban ventaja a los españoles en estos descubrimientos. Sin embargo, el comandante invitó a todos a una reunión en la cabina, y así cortó de raíz todos los rumores. ${ }^{46}$

La siguiente escala de la expedición se hizo en Nootka. Este lugar fue un punto de gran importancia y motivo de controversia en el siglo XVIII. Juan Pérez y su piloto Esteban José Martínez fondearon en 1774 en la rada de Nootka, a la que dieron el nombre de San Lorenzo, cuatro años antes de que Cook la denominara King George's Sound. Después de la expedición de Martínez, otros españoles recorrieron el noroeste y también lo exploraron los ingleses Cook, Dixon, Meares y Duncan. A partir de estas expediciones, el puerto de Nootka se convirtió en el principal mercado de pieles de la costa noroeste de América. Por este motivo, la corte de Madrid se vio en la necesidad de protegerlo, fundando allí un establecimiento y presidio permanente.

A los dos meses de haber llegado Martínez a Nootka, arribó el inglés James Colnett, con orden de establecer una factoría y permitir que otros europeos participaran en el comercio de pieles. Martínez capturó a Colnett y lo envió a la ciudad de México. Esto casi ocasionó una guerra entre Inglaterra y España. Finalmente España tuvo que admitir que la costa noroeste de América fuera abierta a todas las naciones y renunciar a las pretensiones sobre Nootka en favor de los ingleses, pero esto no se supo allí hasta agosto de $1792 .{ }^{47}$

45 Wagner comenta que no sabe lo que Suria quiere decir en este pasaje.Esta es otra parte del texto que Wagner no pudo descifrar por estar unidas las dos palabras "A mî". Esto también lo aclaré en mi Tesis de Maestría.

46 Suria, Diario.

47 Humboldt, Alexander von: Ensayo político sobre el reino de la Nueva España. México, 1966, pág. 212. Gibson, James R.:"Nootka and Nutria. Spain and the Maritime Fur Trade of the Northwest Coast”, en Malaspina' 92, págs. 140-141. San Pío, M. ${ }^{a}$ P. de:Expediciones españolas del siglo XVIII. El paso del Noroeste. Madrid, 1992. 
Cuando llegó Malaspina a Santa Cruz de Nootka, el establecimiento estaba bajo las órdenes de Francisco de Eliza, quien estaba ausente. En su lugar, el capitán Alberni les dio la bienvenida. Suria considera que el puerto no era de los mejores, "la entrada era muy angosta y apenas podían entrar y salir los barcos pequeños a la vez". El dibujante hizo una carta geográfica del lugar.

Desde las primeras décadas del siglo XVIII los españoles sabían que había nutrias marinas en las costas del noroeste de Nueva España. En 1733 se enviaban algunas pieles de Baja California a la ciudad de México. Treinta años después las cazaban con éxito en el norte de California. La Pérouse, en 1786, informó que eran tan abundantes como en las Aleutianas y otros mares visitados por los rusos. ${ }^{48}$

A los españoles les favoreció el haber sido los primeros que hicieron cartas y planos de la costa y darse cuenta de la existencia de fondeaderos cómodos y protegidos con suficiente madera y agua como en la bahía de Bucareli, la rada de Nootka y el puerto Trinidad. Además, durante el viaje de Martínez notaron que los Haidas y Nootkas cogían abundantes pieles y les gustaba el comercio. La abundancia de pieles de nutria fue uno de los motivos que contribuyó a despertar el interés de los franceses, ingleses y españoles por controlar Nootka. ${ }^{49}$

En Nootka, los expedicionarios también realizaron trueque con los nativos nutkeños. El jefe Tlupanamibo los visitó al siguiente día de su llegada, pero supieron que el primer jefe era Macuina. El primero acusaba a este último de querer desalojar a los españoles de Nootka porque los veía con odio y aborrecimiento, pero les anunciaba que no temieran, que mientras él viviese sabría oponerse a Macuina. Suria hizo retratos del jefe Tlupanamibo y los oficiales le ofrecieron regalos.

Los recién llegados se dieron cuenta de que los residentes en Nootka recogían niños de ambos sexos por medio de trueque: eran prisioneros de guerra que servían de manjar a Macuina. Ellos los llevaron a San Blas, donde los familiares de los oficiales los evangelizaban.

Los nativos se alojaron en la playa de Nootka y lo mismo que los tlingit entonaron cantos sobre las glorias de su nación (en ningún lugar mencionan los diarios si había intérpretes o en qué forma se comunicaron con los nativos de Mulgrave y Nootka).

48 Gibson:"Nootka and Nutria. ...”, pág. 141.

49 Ibídem. 
Los expedicionarios hicieron una visita a los establecimientos de Macuina y confirmaron que este jefe temía verlos. Sin embargo, el día 19 los visitó, les hizo regalos y aceptó que subieran algunas mujeres a las corbetas para retratarlas. Suria también dibujó la escena de una visita de Tlupanamibo y su comitiva, cuando bailaban y cantaban.

Durante la estancia en Nootka se realizó una exploración de la costa hasta Tasis, residencia principal de Macuina; se reconoció también el puerto de la Esperanza y se hizo un plano del puerto. Recopilaron información acerca de las costumbres de los nutquenses. ${ }^{50}$ Después de 17 días de estancia en Nootka zarparon hacia el sur, pasaron frente al cabo Mendocino y posteriormente fondearon en Monterrey, donde permanecieron del 12 al 15 de septiembre. Durante su estancia en este puerto completaron los acopios para el Real Gabinete y adquirieron ganado fresco para la tripulación..$^{51}$ Después de pasar por la península de California, las corbetas se separaron y la "Descubierta" se dirigió a San Blas. Llegaron a Acapulco el 19 de septiembre, donde finalmente desembarcó Suria, y se incorporaron a la expedición los artistas Ravenet y Brambila.

\section{La obra artística de Tomás de Suria}

En los siete meses transcurridos desde que el dibujante se unió a la expedición hasta su regreso a Acapulco, el trabajo realizado por los científicos y artistas participantes fue muy amplio en todos los campos: geografía, geodesia, zoología, botánica y etnografía.

La labor de Suria se inició en el puerto de Acapulco y en la fase del viaje hacia la costa del noroeste de América, desempeñó su trabajo a completa satisfacción de los exploradores. Acostumbraba firmar sus dibujos usando la siguiente fórmula: "Suria fecit". Sin embargo, se tiene que lamentar que haya dejado un gran número de dibujos, aparentemente de su pluma, brocha y lápiz, sin firmar. ${ }^{52}$

$50 \mathrm{Al}$ año siguiente, 1792, José M. Mociño fue comisionado para continuar con los estudios de historia natural en Nutka; pudo acopiar más de 200 especies de vegetales y varias de animales. Pero la aportación más importante es el estudio realizado sobre los nutkeños. Da información acerca de sus hábitos, ritos religiosos, gobierno e idioma. Arias Divito, Juan Carlos: Las expediciones científicas españolas durante el siglo XVIII. Madrid, 1968, págs. 167-173.

51 Tova y Arredondo, Diario.

52 Cutter: Malaspina in California, pág. 14. 
En el puerto de Acapulco Suria elaboró siete dibujos de peces de distintas clases, en colores, y además un borrador de un pez en colores, según Sotos Serrano carente de valor artístico, pero importante porque incluye en la misma lámina unos estudios de manos. ${ }^{53}$ También dibujó tres láminas de aves en colores y una de un pajarito con cierta gracia, el cual tiene anotaciones de Suria que sirven para identificarlo. Tiene asimismo un dibujo y un boceto en posición diferente al primero, de un tejón; a estos trabajos hay que añadir un diseño de una serpiente con la porción anatómica de un pez. Antes de partir las corbetas al noroeste, Suria diseñó una panorámica en colores de la bahía y puerto de Acapulco, Cardero y Bauzá sacaron otras semejantes. Muy interesante es el dibujo titulado "Pelea de gallos en Acapulco", en el que representa dos indígenas con un gallo en las manos, en el momento en que va a empezar el espectáculo, y un público numeroso y heterogéneo: negros, españoles y castas. ${ }^{54}$

Suria puede considerarse como un artista muy prolífico en dibujos de las regiones del noroeste de América, en especial de Mulgrave y Nootka; se conservan numerosas obras suyas. En Mulgrave hizo una serie de diseños de los cuales dejó varios en su Diario. ${ }^{55}$ Existen también en la colección del Museo Naval de Madrid varios dibujos que, al compararlos con los del Diario, se pueden atribuir a Suria, especialmente los que representan a los naturales de Mulgrave.

En este puerto Suria retrató a los nativos y a través de estos dibujos se pueden apreciar las distintas clases sociales que formaban la etnia. Alrededor de la mitad de estos dibujos están incluidos en su Diario. Las diversas láminas muestran el modo de vida de los nativos. Sotos Guerrero considera que en los dibujos femeninos puso especial atención y cuidado, con un trazo firme y de gran estilo. Son cuatro retratos de mujeres: uno de ellos se titula "Mujer plebeya"; otro representa una mujer con su hijo en los brazos y para Sotos Serrano, éste es el mejor de los retratos que Suria hizo en Mulgrave. En un estudio de cabezas femeninas, traza los rasgos de las nativas en diversas posiciones. ${ }^{56}$

53 Sotos Serrano:Los pintores ..., vol. I, págs. 141-142 y vol. II, págs. 131-132, 137-138, 146, 176 e ilustraciones de cada uno de los dibujos de la expedición, de todos los artistas, y una descripción de cada lámina.

54 Ibídem, vol. I, págs. 141-142. Casi todos los dibujos de Suria elaborados en Acapulco se conservan en el Museo Naval de Madrid.

55 La mayoría de ellos han sido ya publicados por Henry R. Wagner y Justino Fernández.

56 Suria, Diario. Sotos Serrano:Los pintores ..., vol. I, pág. 143. 
Los retratos masculinos, lo mismo que los de mujeres, contribuyen a confirmar las descripciones de Suria en su Diario: eran de mediana estatura, robustos y fuertes, con el rostro redondo y ojos vivos rasgados, parece que no tenían mucho pelo y su barba era escasa. Cuando retrata al indio común lo titula "Plebeyo" o "indio", pero en el caso de ser un hombre importante, lo menciona, por ejemplo: "Jefe del puerto de Mulgrabe nombrado Ankaiui", o "Indio armado en Guerra del Puerto de Mulgrabe". ${ }^{57}$

Se conserva una marina con parte de costa y las dos corbetas, que se atribuye a Suria; lo mismo que una panorámica de la entrada del puerto, en donde aparecen los barcos ligeramente esbozados. Los acontecimientos inusitados son también dibujados por el artista, como podemos apreciar en "Discordia con los naturales del Pto. de Mulgrabe en 5 de junio de 1791", que incluye en su Diario.

Otra aportación de Suria consistió en la influencia que ejerció sobre Cardero, quien lo apreciaba como maestro y se esforzó en asimilar todo lo que le enseñaba. Es muy posible que a esto se deba la forma en que Cardero mejoró su estilo, adquiriendo una soltura y calidad "propias ya de un especialista". ${ }^{58}$

Los dibujos precalifornianos de Suria durante la expedición de Malaspina, pueden ser fijados en lugar y fecha por su mismo Diario y otras crónicas de la expedición. Respecto a California existe alguna dificultad, porque no hay un solo dibujo firmado por él durante su estancia en estos lugares. Se le reconoce que trazaba bien los rasgos faciales y los trajes de los neófitos recientemente llevados a la misión del Carmelo. Esto demuestra que hay muchas más obras suyas de las que se supone.

Al terminar la etapa de la expedición al noroeste, Malaspina recomendó a Suria ante Antonio Valdés, en los siguientes términos: "Finalmente nuestras colecciones para el Museo Real han sido numerosas e interesantes, tanto que Don Tomás de Suria ha descrito con gran fidelidad a la naturaleza, todo lo que merece ayuda del grabador para asegurar mejor entendimiento de la narración histórica del viaje". ${ }^{9}$

La mayoría de los trabajos de Suria se encuentran actualmente en la colección del Museo Naval de Madrid y otros en el Museo de América, de la misma ciudad. Estos se remitieron a España en 1791. Hay un oficio en el Archivo General de la Nación, en México, sobre el envío de varios cajones de curiosidades de la Expedición de don Alejandro Malaspina, y entre

57 Ibídem.E Ibídem, págs. 143-144.

58 Sotos Serrano:Los pintores ..., vol. I, pág. 129.

59 Ibídem, pág 15. 
otras cosas dice: "se envían dibujos de Suria y Cardero de los objetos más importantes de la campaña pasada. Se ha hecho poner cristal a los que se han ejecutado con lápiz para que no se borrasen. Faltan algunos que Suria está poniendo en limpio". ${ }^{60}$

Los dibujos del artista reflejan una característica muy acentuada: el vigor de los rasgos de sus figuras. Da forma a estos rasgos a través de manchas, casi no utiliza las líneas, las enfatiza únicamente para obtener claroscuro, especialmente en el pelo y en las pieles de los naturales. La mayoría de sus trabajos están hechos en tinta o agua tinta. Se nota gran diferencia con los trabajos de Cardero, que utilizaba más el pincel; algunos de sus trabajos están hechos al carboncillo.

Así, a través de sus dibujos y las descripciones escritas en su Diario, Suria cumplió con el objetivo de su misión: dar una idea exacta de las regiones visitadas y sus habitantes. Si añadimos a la labor artística las descripciones que proporciona en el Diario sobre los naturales y las regiones visitadas, no queda ninguna duda del valor de su contribución a la expedición alrededor del mundo.

Suria no fue muy afortunado respecto a su trabajo; en 1785, José Estebe, Bernardo Gil y él, pensionados del Ramo de Grabado de la Real Casa de Moneda, hicieron una petición diciendo que desde el establecimiento de la Academia se dedicaron a trabajar horas extras para hacer los ejemplares necesarios para instruir a los jóvenes que concurrían a ella, que eran más de 112. A pesar de esto Suria sólo recibió 40 pesos, Estebe 25, y 22 Gil. ${ }^{61}$

Algunos años más tarde, Suria y sus compañeros pensionados de San Carlos se quejaron ante el virrey de las diferencias en las enseñanzas dentro de la misma institución, pidiendo se hiciera justicia. ${ }^{62}$ El hecho de que don Tomás era reconocido como buen dibujante y tallador, contribuyó para que fuese escogido para unirse a la expedición de Malaspina.

Al regresar la expedición a Acapulco, Malaspina envió una carta al virrey el 10 de noviembre de 1791, en la cual decía que Tomás de Suria regresaba ya a la Ciudad de México, y agregaba:

"En esta ocasión me ha parecido debido asegurar a V. E., como lo hago ahora, que este hábil sujeto ha correspondido completamente a la acertada atención de V. E. y que la expedición espera un lustre no indiferente no sólo de sus asiduas tareas en todo el tiem-

60 AGN, Historia, 277.

61 AASC, doc. 245. Al margen acuerdo asignándoles gratificaciones.

62 Ibídem. Ignacio Sandoval, José María Vásquez, Bernardo Gil y Juan Mariano Sandoval al virrey, en 19 de junio de 1788 . 
po de la navegación, sino también de las que continuará con la actual quietud, si V. E. tiene a bien concederle que por otros seis meses se ocupe de los objetos de la expedición en lugar de los que corresponderían directamente por su destino en esta capital". ${ }^{63}$

En la misma carta dice el capitán que Dionisio Alcalá Galiano cancelará la cuenta de Suria. Revillagigedo contestó al comandante diciéndole que vio el buen informe de Suria, quien podía continuar los trabajos todo el tiempo que fuera necesario. ${ }^{64} \mathrm{El}$ artista pasó los ocho meses que siguieron a la expedición terminando sus diseños, los que despachó luego a Madrid. Los grabadores españoles iban a usar estos dibujos para hacer las placas finales de cobre, e imprimir la memoria que se había propuesto elaborar sobre la expedición. Se esperaba que el trabajo terminado rivalizara con la computación del capitán James Cook y diera mayor crédito a la nación española. ${ }^{65}$

En la Gaceta de México de diciembre de 1791 se dio un informe sobre la expedición, que terminaba en la forma siguiente:

"y algún día se presentarán al público (los datos) con sus correspondientes mapas, y una primorosa colección de exactos dibujos ejecutados por don Tomás de Suria sobre lo que podrá formarse cabal idea, así de los trabajos científicos y los diversos acaecimientos durante la mansión en los puertos, como de las fisonomías, trajes, habitaciones y útiles de aquellos habitantes". ${ }^{6}$

Se encuentra un oficio en el Archivo de la Academia de San Carlos cuya información parece contradictoria respecto a lo que anteriormente se había dicho de Suria; don Jerónimo Antonio Gil dice que " tomará a su cargo a Suria de cuya expresión se deduce que no tiene aún la aptitud necesaria para trabajar por sí, y en este caso tampoco sería regular que percibiese la misma asignación de cuatro reales". ${ }^{67}$ Es extraña la opinión del director de la Academia, por haber sido él mismo quien un año antes dio excelentes recomendaciones de Suria al virrey y al comandante.

Parece que la mala suerte de Malaspina se extendió a sus colaboradores. Algún tiempo después de que Suria terminase los dibujos para el Real Gabinete, se dirigió a Revillagigedo quejándose de su mala situación, de que se encontraba sin recursos y solicitó un ascenso; decía que había trabajado 16 años en la Casa de Moneda sin haber sido promovido; que había

\footnotetext{
63 AGN, Historia, 397. Malaspina al virrey, primero de noviembre de 1791.

64 Ibídem, el virrey Revillagigedo a Malaspina.

65 Cutter:"Spanish Artists ...”, pág. 153.

66 Fernández:Tomás de Suria ..., pág. 106.

67 AASC, oficio de la Junta remitido al virrey Revillagigedo, 12 de septiembre de 1792.
} 
cooperado en el establecimiento de la Academia de San Carlos, haciendo dibujos para modelos, sin recibir gratificación; construyó planos para el nuevo reglamento del ejército y, desempeñó con gran éxito su comisión en la expedición de Malaspina, por la cual él pensó que podría llegar hasta España, y finalmente empleó ocho meses en poner en limpio los trabajos del viaje. Añadía que se remediaría con una plaza de oficial mayor de 1,500, pero consideraba que era imposible adquirirla y por lo tanto pedía que se le diera otro destino y que se certificara su actuación en el viaje al noroeste. ${ }^{68}$

El virrey ordenó el 2 de julio que se le otorgase el certificado que solicitaba y le daba esperanzas de contribuir a sus alivios. Lo recibió una semana después. ${ }^{69}$ A pesar de las promesas de Revillagigedo, Suria siguió como tallador hasta la muerte de su maestro don Jerónimo Antonio Gil en 1798. Pasó entonces a ocupar el puesto de grabador mayor en la Casa de Moneda de México y en 1805 le dieron el cargo de contador ordinario de pagos de tercera clase.

Aunque económicamente mejorara la situación de Suria, él no estaba satisfecho; consideró que no se le reconocían sus méritos y el 28 de febrero de 1826, se dirigió al presidente de la Junta de la Academia de San Carlos, quejándose del gobierno anterior y del actual pues habiendo sido uno de los fundadores de tan útil y benéfico establecimiento, en unión de don Jerónimo Antonio Gil, jamás la Academia le había tenido la más mínima consideración para darle al menos uno de los tres honores que concedía. A continuación exponía todos los servicios prestados desde la fundación de la Real Academia. Consideraba que después de Gil, nadie podía en justicia tener más méritos que él mismo. Les recuerda que la Academia, para inmortalizar a su fundador Gil, lo comisionó, por los años de 1792, para que sacase al natural un dibujo de su retrato, que con 500 ejemplares impresos y la lámina, remitió a la Academia, donde debía existir en su archivo. Por último, decía que deseaba recibir los honores sin presentar ya ninguna obra. Terminaba añadiendo: "para la contestación que espero, vivo frente a los Arcos de Belén de Mochas junto a la fábrica de Indianillas del Señor Iglesias No. 26". ${ }^{70}$

No se ha encontrado un documento que certifique si recibió o no los merecidos honores que reclamaba. Siguió trabajando Suria, puesto que todavía en 1830 firma los grabados que adornan el papel de la Inspección General de Infantería y Caballería Permanente.

68 AGN, Historia, 397, Suria al virrey Revillagigedo, 21 de junio de 1794.

69 Ibídem.

70 AASC, doc. 1962. Suria a Andrés Mendívil, 28 de febrero de 1826. 